\title{
Cognitive Behaviour Therapy and Mindfulness: hope for Depression
}

\author{
Monica Sharma ${ }^{1}$, Dr. Asha Hingar ${ }^{2}$, Dr. I.D. Gupta ${ }^{3}$
}

\section{ABSTRACT}

Depression is the common cold of mental disorders. It is one of the main issues that needs to receive a great deal of attention in order to create grounds to be prevented or cured. It is interesting to note that there is extensive literature emphasising the role and effectiveness of CBT as the treatment of depression. But few researchers talk about combined effect of CBT and Mindfulness. So to reduce this gap the present study aims to examine the application of CBT and Mindfulness to reduce the symptoms of Depression. This study adopts CBT and Mindfulness together in a case of 40 year old, married, educated woman experiencing depression from last 5 years. She was having difficulty in performing her everyday tasks and managing her work. Detailed therapy sessions were conducted to resolve the issues. The analysis of data revealed that both the techniques when used in combination were effective in reducing depression experienced by the client as there was significant reduction in the level of depression she suffered and reduced stress levels.

Keywords: Depression, CBT, Mindfulness.

"When you're struggling with something, look at all the people around you and realize that every single person you see is struggling with something, and to them, it's just as hard as what you're going through”. -Nicholas Sparks

In the $21^{\text {st }}$ century life has become very much complicated and people suffer from stress and strain. Some people can cope with the life situations and stressors easily and effectively while other's can't. In many cases it has been seen that the expectations of common people are growing up day by day and when they are not fulfilled they eventually fall prey of depression.

\footnotetext{
${ }^{1}$ Research Scholar, IIS University, Jaipur, India

${ }^{2}$ Retired Professor of Psychology, University Of Rajasthan, Jaipur, India

${ }^{3}$ Professor, SMS Medical College, Jaipur, India

*Responding Author

(C) 2016 I M Sharma, A Hingar; licensee IJIP. This is an Open Access Research distributed under the terms of the Creative Commons Attribution License (http://creativecommons.org/licenses/by/2.0), which permits unrestricted use, distribution, and reproduction in any Medium, provided the original work is properly cited.
} 


\section{Cognitive Behaviour Therapy and Mindfulness: hope for Depression}

In the fast pace world every individual is under so much of pressure to perform and produce results that even minor setbacks and losses are given greater values than needed, to add uponto this situation are the actions of people who are around that sicken, an individual to his/her soul and make them think that the world is a sad place to live in. Even without the presence of any actual illness, depression, robs off all self worth, self-esteem, self-confidence and self-image. During the experience of depression one might don't want to get out of bed or there are nights he/she can't sleep. One might even wonder about the exact meaning and purpose of their life.

Depression has become one of the alarming crises in today's society where every individual has experienced feelings of depression at one time or another. According to WHO it is expected that in 2020, depression will become the second most common cause of disability, after cardiovascular diseases. It affects about 121 million people in the world, and less than $25 \%$ of them have access to effective treatments. WHO even warns that 1 out of every 5 people will develop depressive symptoms in their lifetime, and this number increases if there are other concurrent factors, such as medical illnesses or stressful situations.

Depression is a severe and prolonged state characterized by Normal sadness which grows into a painful state of hopelessness, listlessness, lack of motivation and fatigue. As depression worsens, feelings of extreme sadness and hopelessness combine with low self-esteem, guilt, memory and concentration difficulties to bring about a severely painful state of mind. Each person's experience is different from another as there is a wide variety of symptoms. Many people feel down occasionally, or go through bad patches. They feel bad about themselves and their life in many ways and at times they can feel completely despair, but they even have areas in their life that make them feel good about themselves. For some people life is more of a struggle.

Depression is a disorder that affects the body, mood and thoughts. New researches show that when an individual suffers from depression, during an episode negative mood occurs along with negative thinking (eg. 'I am failure') and bodily sensations of sluggishness and fatigue. When this episode of depression has passed, the negative mood returns to normal, the negative thinking and fatigue also disappears. However it is believed that a connection is formed between the negative mood and negative thoughts patterns which were present during the episode.

So it can be concluded from the above theory that whenever this negative mood happens again for whatever reason, it can trigger the old negative thinking pattern again. Clients who had believed to recover from depression so such mood state may find themselves back in the similar condition. In the rumination loop which feels as if they will find an answer to their questions such as why it is happening to them only? Etc., but contrary to this, the rumination succeeds in prolonging and deepening the mood spiral only. When this happens, the old negative thinking starts up again, getting the client into the same condition that is full-blown episode of depression. A number of psychological approaches have been demonstrated to be effective in the treatment of depression out of which CBT has been found to be effective on its own for patients 


\section{Cognitive Behaviour Therapy and Mindfulness: hope for Depression}

experiencing mild to moderate depressive symptoms and useful adjunct to medication for sever episodes. CBT and antidepressants are both cost effective treatments for depression. Whereas SSRIs when considered as maintenance treatment is the most expensive option (Vos et al., 2005).CBT alone has also shown significant reduction in the depressive symptoms after 10 sessions over a period of 4 months (Zapor and Stuart, 2014).

All these improvements are possible because CBT is based on the idea that how an individual thinks (cognition), how he/she feels (emotion), and how they act (behaviour) all interact together. That is thoughts determine feelings and behaviours of an individual. Therefore, negative and unrealistic thoughts can cause distress and results in problems. When a person suffers with psychological distress, the way in which they interpret situations becomes skewed, which in turn has a negative impact on the actions they take.

The common maintenance process of depression proves to be helpful in understanding how CBT is effective treatment for depression. This process suggest that there is a possible link between depressed mood with negative biases and interpretation of symptoms, which leads to a negative view of the self. These negative biases and symptoms of depression lead to reduction of activity, which maintains the low mood because activities that previously gave pleasure or a sense of achievement are lost. It also leads to reduced attempts to cope and deal with problems, which leads to increased hopelessness, low self-esteem and self-efficacy, thus maintaining the depressed mood.

CBT as the treatment of depression aims to help people become aware of when they make negative interpretations, the reduction in their normal behaviour in addition with the behavioural patterns which reinforce the distorted thinking. This therapy helps individuals to develop alternative ways of thinking and behaving which aims at reducing their psychological distress. Szu-Yu Chen (2014) conducted a study on 30 depressed individuals. The results of the study suggested that the more individuals improved their problem-solving appraisal, the more their depression decreased. It was also found that the individuals poor on problem solving appraisal before the CBT, showed improvement in problem solving appraisal and decreased level of depression after CBT.

In sum, findings suggested that problem-solving appraisal might play an important part in CBT for depression reduction. Furthermore, CBT seemed to have a ceiling effect on improving individuals' problem-solving appraisal.

In recent years other than CBT, Mindfulness meditation has also shown significant improvements in depressed patients. Depression has been the most studied disorder in the combined treatment literature. Many randomized controlled studies on depression have supported the advantage of combined therapy over mono-therapy. Due to the third wave of CBT 


\section{Cognitive Behaviour Therapy and Mindfulness: hope for Depression}

psychotherapists have turned to mindfulness as an important element in the treatment of a number of mental disorders.

It is common for mindfulness to be combined with psychotherapy, especially cognitive behavioural therapy. This development makes good sense, since both mindfulness meditation and CBT share the common goal of helping people gain perspective on irrational, maladaptive, and self-defeating thoughts. Trials of Mindfulness Based Cognitive Therapy have evaluated its efficacy in preventing relapse in depression by around 50\% (Teasdaleet.al 2000; Ma and Teasdale 2004).

When both CBT and anti-depressants medications are used as the mode of treatment for depressed patients Keller et al., (2000), found a greater remission rate. Where as in a study conducted by Kuyken et.al (2008) with the aim to compare the outcome of two groups viz, MBCT and medication in depressed patients. Results of 15 months following showed that relapse rate were comparable with a trend towards a better outcome for MBCT (47\% relapse) compared to continued medication (60\% relapse).

In a meta analysis review it was proved that mindfulness based interventions are most affective for reducing depressive symptoms among patient of mood disorders (Hofman and Smits, 2008). Although mindfulness is of great interest internationally, the researchers conducted in India are still scarce. Thus the need was felt to conduct a study based on mindfulness in combination with CBT.

\section{CASE INTRODUCTION}

Mrs. X, 40 years old, female, married, housewife from middle socioeconomic status, came with her mother and elder sister with the following complaints. She is having episodic illness, this is $2^{\text {nd }}$ episode.

$\begin{array}{ll}\text { - } & \text { Shock lag karuthatihu } \\ \text { - } & \text { Heart beating bar jatihai } \\ \text { - } & \text { Maankisibhikaam main nahilagta } \\ \text { - } & \text { Insecure se feeling hotihai } \\ \text { - } & \text { Shakti nahirahati } \\ \text { - } & \text { Udashojatihupatanahi q }\end{array}$

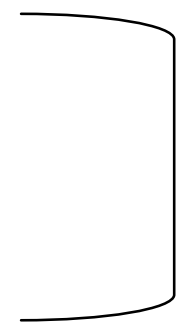

1 year 6 moths.

The patient was apparently asymptomatic before her first episode which was 13 years back. Since then she is on and off on medication (OPD). 1 year 6 months back she suddenly came to know that her husband has been admitted in the hospital (ICU). She rushed to the hospital with rest of her family members and came to know that the reason for hospitalization was heartattack. She stayed in hospital the whole night.

(C) The International Journal of Indian Psychology, ISSN 2348-5396 (e)| ISSN: 2349-3429 (p) | 31 


\section{Cognitive Behaviour Therapy and Mindfulness: hope for Depression}

The next morning she woke up with a feeling of shock and her heart was beating very fast. She didn't feel like doing any work or talking to anybody. There was a sense of being insecure; there was loss of energy in her body. All this happens in a chain one after another. Her symptoms are worst in morning but gets a bit better by evening. Her symptoms were same in both the episodes. Predominant mood is dysthymic. Socio-occupational functioning and Biological functions like appetite and libido are reduced; there is inability to fall asleep. Personal hygiene is maintained.

No history suggestive of organ city or use of psychoactive substance in relation to present symptoms. No history suggestive of panic disorder, No history suggestive of first rank symptoms and any kind of delusions and hallucinations. No history suggestive of sustained elated mood. No history suggestive of any obsessions or compulsions.

On MSE, she was well kempt and tidy, touch with surroundings was present, rapport was easily established and attitude towards examiner was cooperative. Subjectively, her affect was dysthymic with diurnal variation worst in morning and objectively, her affect was euthymic. Her stream of thought was normal, tempo decreased slightly. Ideas of hopelessness and worthlessness with suicidal ideation and religious pre-occupation were present with grade $\mathrm{V}$ level of insight.

Diagnosis of Recurrent depressive disorder, current episode moderate with somatic syndrome. (F33.11) was made.

\section{CLINICAL ASSESSMENT AND THERAPY SESSION SUMMARY}

\section{Treatment outcome measures}

To evaluate the treatment progress, the following measures were administered before the therapy was started and after the termination $\left(12^{\text {th }}\right.$ session $)$

- The Diagnostic and Statistical Manual Brief Symptom Interview for Depression (DSM Interview; Stark \& Sander, 2002)

The Beck Depression Inventory (BDI-II; Beck et al.,1996)

The Five Facet Mindfulness Questionnaire (FFMQ)

Self-Efficacy (Jerusalam and Schwarzer, 1992)

The Rosenberg Self-Esteem Scale (Rosenberg, 1965)

The Perceived Stress Scale - 4 (PSS4) (spring, 2008)

The Inventory of Cognitive Distortions (ICD; Yurica\&DiTomasso,2002)

Social Problem-Solving Inventory-Revised (SPSI-R) (D’Zurilla et al. ,2002) 


\section{Cognitive Behaviour Therapy and Mindfulness: hope for Depression}

\section{Therapeutic formulation}

BECK’S MODEL OF DEPRESSION

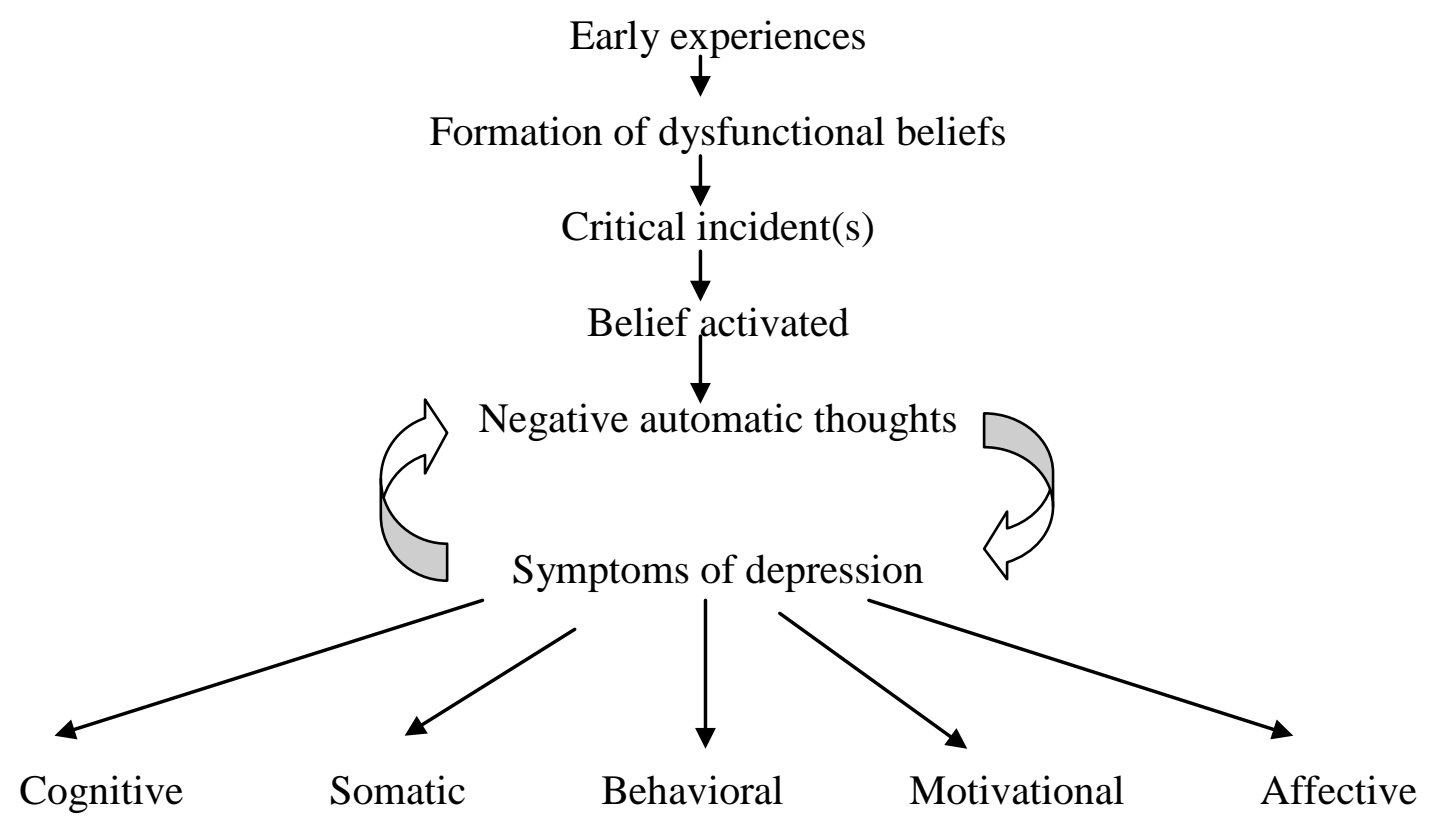

On the basis of detailed information collected Beck's model for depression can be applied for the formulation. It can be concluded that both her last episodes were triggered with some or other kind of loss. During her childhood she loved her mother a lot but because her father was working out of station her mother had to stay away, which lead to the development of feeling of loneliness and thoughts like "everyone i love leaves me". Then her neighbour died and she saw his wife suffering a lot (loneliness and financial problems etc.) which lead to the development of dysfunctional belief "husband is important for women to live happily and successfully". when her husband suffered heart-attack her belief got triggered which lead to negative automatic thought such as, "what if something happens to him, what will happen to me, what will my child do" development of depressive symptoms.

\section{Procedure:}

A single case design with pre and post therapy assessment was adopted. CBT and Mindfulness therapy was administered in 12 session of one hour duration. The intervention programme was developed with the following goals:

\section{Goals of Therapy:}

After interviewing the client, the therapist along with the client decided the goals for therapy.

It was decided to first focus on her daily activities as she had stopped working at all which was in turn increasing her level of depression. Hence the goals of therapy were prioritized in terms of client's needs. So goals of treatment were:-

1. Psycho education to the family regarding her illness.

2. Scheduling the patient's daily activities to regulate her behaviour. 


\section{Cognitive Behaviour Therapy and Mindfulness: hope for Depression}

3. To train patient in Mindfulness.

4. Providing stimulating environment to the patient to enhance her functioning skills.

5. Training the patient to enhance her working skills using graded tasks assignments.

6. Monitoring thought patterns for better understanding the irrational thoughts and beliefs and then working on them.

7. Include behavioural experiments to test the irrational thoughts.

8. Cognitive restructuring to help change the distortions.

9. To train patient in problem solving skills.

10. Compliance training to patient to prevent relapse.

\section{Strategies used and their rationale:}

\section{Psycho education to the parents regarding her illness.}

Psycho education is one of the most important parts of any treatment plan. In this the basic and major information related to the client's condition and the reality of the problem is conveyed in the family members and how the treatment will go about. Any myths related to the disorder are also removed. The rational of proper psycho education is to make family members aware about the present condition and future treatment plans, risk etc so that they can help in management.

\section{Scheduling the patient's daily activities to regulate her behaviour.}

It will make the environment more predictable. It will help in channelizing her physical energy into meaningful activity. It reduces an apparently over-whelming mass of tasks to a manageable list, removes the need for repeated decision-making, makes it more likely that activities will be carried out, encourages an increase in the proportion of satisfying activities, and increases patient's sense of control over their lives. In activity scheduling the current activities taken up by the client are rated on two important dimensions: (1) his/her sense of mastery (how well you think you accomplish a task) and (2) clients sense of pleasure and enjoyment.

\section{To train patient in Mindfulness.}

Mindfulness meditation is proved to be effective in helping the patient to be aware of moment to moment, be non-judgemental and to accept things as they are.

\section{Training the patient to enhance her working skills using graded tasks assignments.}

Graded task assignment counters hopelessness by encouraging patients to reduce tasks to manageable proportions, to increase the frequency of self-reward, and redefine success realistically, taking into account how they feel.

5. Monitoring thought patterns for better understanding the irrational thoughts and beliefs and then working on them.

What do client believe, and why do they believe so? Is important in CBT. The client often need assistance at identifying the link between their thoughts and their emotions before they move on to challenging these thoughts and substituting more helpful thoughts for these less helpful ones. The purpose of keeping a thought record is simply to help client catch his/her thoughts, recognise the feelings that go all along with them, and then further to work on balancing out their thinking towards modifying their mood. 


\section{Cognitive Behaviour Therapy and Mindfulness: hope for Depression}

\section{Include behavioural experiments to test the irrational thoughts.}

Questioning negative thoughts encourages patients to evaluate realistically the costs and advantages of acting differently, and to prepare for a range of possible outcome. These in turn produces consequences that contradict the original thoughts and thus further erode their credibility. It is a way of testing the validity of negative automatic thoughts, and not an end in itself.

\section{Cognitive restructuring to help change the distortions.}

Beck’s $(1987,1996)$ cognitive model postulates that biased self-relevant thoughts, evaluations, and beliefs are key contributors to the development and persistence of psychopathological states. That, is the reason why change in these thoughts, evaluations and beliefs is considered essential for significant and enduring symptom reduction (Beck et al., 1979; Clark et al., 1999). The cognitive restructuring is a structured, collaborative therapeutic approach in which the client is taught how to identify, evaluate, and modify the faulty thoughts, evaluations, and beliefs that are considered responsible for the development of depression (Burns \& Beck, 1978; Hollon\&Dimidjian, 2009; Dobson \&Dozois, 2010).

\section{To train patient in problem solving skill.}

Depression can make small problems appear much bigger than they are which can get pretty overwhelming. Problem-solving will help the client to adopt a realistically optimistic view of coping, understand the role of emotions more effectively, and creatively develop an action plan geared to reduce psychological distress and enhance well-being. It will help client to manage the symptoms of depression as these symptoms are often the result of an inability (or perceived inability) to deal effectively with problems. Further it also improving the patient's coping skills and enhancing their ability to handle upsetting life experiences.

\section{Compliance training to patient.}

Compliance training is given to parents and child so that they adhere to psychological treatment. So that maximum benefit is expected to the client.

\section{Therapy session}

\section{Initial sessions: (from session 1 to 3 )}

The first sessions focused on history taking and clarifications. The sessions were held with the patient and her family. The patient was asked about her problem areas. The main tests for the study were also conducted so that the pre scores are obtained on the bases of which the progress could be evaluated.

\section{Middle sessions: (from session 4 to 11)}

The short and long term goals were decided. Therapeutic contact was made. It was decided that the client will be seen once in a week as per client's convenience and each session would usually be of one hour. The client and his family were told that it would take around 12 sessions to work on her problem. As planned the therapeutic work was started. The client and her family were psycho-educated about Depression and how therapy will work and its importance was also discussed. The important message conveyed to the client was that having this disorder is not like 


\section{Cognitive Behaviour Therapy and Mindfulness: hope for Depression}

you have failed or it's because of you or because of any other thing. It was added that it is a manageable disorder with the help of pharmacological and psychological treatment. The importance of compliance was told and issues related were discussed. The results of the test were also discussed with her.

In the $4^{\text {th }}$ and $5^{\text {th }}$ session mindfulness training was taught in which the client was trained to practice mindfulness in the session and at home. During the $4^{\text {th }}$ session only activity scheduling was also started. It was first asked to the client what all activities she does in a day and she wishes to do. After collecting all this information on mutual consent and the need of the client the daily schedule was prepared which the client had to follow. Mindfulness meditation was also included in daily activities.

In the session $6^{\text {th }}$ apart from mindfulness and activity scheduling, graded task assignment were also added to the treatment plan. Client was asked about the difficulties faced in daily schedules and how she does them, and then they were broken into small steps for her. This made task easy and doable for her. This would also add to uplift her sense of self-efficacy as now she was able to do task which she earlier thought to be difficult. In addition to this thought diary was added in her homework task. In this she was asked to prepare a chart containing information about her thoughts, situations which give rise to them, how her feeling change after that etc.

In the next session, that is $7^{\text {th }}$ sessioncognitive restructuring was started. She was trained to monitor the thoughts and to substitute more positive interpretations for her negative interpretations. All the beliefs which she had regarding her husband's illness and herself etc all were questioned so that evidences could be checked and faults thoughts could be removed. For some behaviour experiment was also incorporated to check the evidences. The same plan was continued in session $8^{\text {th }}$ as well.

In session $9^{\text {th }}$ and $10^{\text {th }}$ problem solving skills were taught to her taking her real life problems which she thought had no solution or were very difficult. Step wise the whole process was taught.

During the $11^{\text {th }}$ session a review of all the techniques and skills taught and discussed during the therapy session were reviewed. Also for the evaluation of the treatment planned a post assessment was conducted.

\section{Termination sessions (session $12^{\text {th }}$ )}

During this session the post assessment results were discussed. To show the improvement in her condition due to therapy. It was also advised that if there is any issue which she feels to discuss at any point she can come. It was also added that she should practice mindfulness regularly with other techniques learned during the therapy. 
Pre and Post Assessment

Table1: Scores for pre-post assessment on Depression, Stress and Mindfulness

\begin{tabular}{|l|l|l|}
\hline Variable & Pre-Scores & Post-Scores \\
\hline BDI & 27 & 16 \\
\hline Mindfulness & 97 & 120 \\
\hline Self Efficacy & 25 & 30 \\
\hline Self Esteem & 22 & 25 \\
\hline Perceived Stress & 11 & 9 \\
\hline ICD & 221 & 150 \\
\hline Social Problem Solving & 6.8 & 13.8 \\
\hline
\end{tabular}

\section{DISCUSSION}

Depression is a very common and debilitating condition. More than one out of eight people will have an episode of depression in a lifetime and the majority of the patients who have an episode of depression end up having at least one more episode later in life (Kessler, 2005). As mentioned above depression can drastically affect an individual's ability to function interpersonally, socially and at work. This condition not only affects the patient but it also affects the lives of their families and caregivers. CBT was developed in the 60's as a treatment approach for depression (Burns, 1980). Since then there is a plethora of studies evaluating the efficacy and effectiveness of CBT, they have shown generally solid results for CBT as an effective treatment for depression with different groups, in different modes of delivery, and in manifold settings. Now a day, a new approach Mindfulness has been developed and has shown to be effective in treating depression and preventing its relapse. Many studies have found that mindfulness meditation can cut the recurrence of depression by 50\% (Kabat-Zinn, et al, 2002). So, the present case study was designed with the objective of studying the efficacy of CBT and Mindfulness in the management of depression. Results of the intervention indicated that CBT and Mindfulness was useful in managing depression.

As evident from the result table, in the present case CBT and Mindfulness appeared to reduce depressive symptoms, the level of perceived stress as well as cognitive distortions or dysfunctional thoughts and improvement in the sense of self-efficacy, self-esteem and problem solving ability of the client. The number of CBT and Mindfulness sessions needed to achieve these results was 12 . In addition the client continued to show improvements several months post treatment in depressive symptoms and other related areas indication improvement in the client's condition. This result is in conjunction with a research conducted by Kuyken et al. (2008) in which the relapse rate of depressive who were taught mindfulness in addition to their usual treatment, were compared to the control group and the results revealed that in the control group 22\% didn’t relapsed whereas, in the mindfulness group 64\% didn't. 


\section{Cognitive Behaviour Therapy and Mindfulness: hope for Depression}

When CBT is combined with mindfulness better results can be obtained in a case of depression. As mindfulness helps the client to be non- judgemental, stay in the present moment, non reactively and acceptance (Kabat-Zinn, 2005) of situations as they are. When we analysed the thought pattern of the client, as in majority of depressed cases, her content was also negative about the past and future. Mindfulness helped the client to stay in present moment, not to judge or react and techniques of CBT accompany in changing/ modifying these thought patterns to more positive ones.

CBT for depression includes both behavioural and cognitive interventions; similarly in the present case both interventions were combined with mindfulness to treat depression. Activity scheduling treatment strategy from behavioural intervention was the first technique to be incorporated in the case. It primarily focused on increasing mood-related pleasant events and activities and also providing a sense of accomplishment or mastery (Kanter, et al., 2005). Activity scheduling is as effective as the full treatment package for depression (Huppert, 2009), which not only works for mood upliftment but also improves the self efficacy and self esteem of the client. As Bandura (1997) has mentioned that, the primary source of efficacy information includes past performance accomplishments, or mastery experiences (which activity scheduling provides) or social persuasion, social modelling and the interpretation of physiological or emotional states.Adding to this is a case study conducted by Wright et al., (2005) reporting improvements in clients sense of self esteem after practicing activity scheduling.

Another reason to obtain these results could be that when techniques which are at the core of CBT that is, cognitive restructuring, skills training and engagements in pleasure activities were added and used in combination with each other in the treatment. They not only helped in attaining better skills but also a sense of control over one's life. As when the client engage in pleasure activities she was able to understand the link between her activities and her mood, this further helps in enhancing the sense of self-efficacy and self esteem because task which were thought to be impossible were easy and doable for her now providing a sense of mastery. The graded task techniques also help in it by breaking difficult task in small steps.

Cognitive restructuring helped the client to monitor the thoughts and to substitute them with the more positive ones. When cognitive restructuring is combined with psycho-education, monitoring(in the form of thought diary), behavioural activation and homework assignments greater remission is achieved.(Huppert, 2009)

When she was trained in problem solving skills, she was able to solve the problems which were difficult and non solvable earlier.(Gotlib etal, 1979; D’Zurilla etal, 1982, ) depressed people exhibit a reduced capacity to resolve personal and social problems. So when the client was trained in this skill she improved because she was able to achieve problem resolution and gained a sense of empowerment. Problem solving therapy has been shown to be effective for many 


\section{Cognitive Behaviour Therapy and Mindfulness: hope for Depression}

common mental health conditions including depression (Mynors- Wallis et al, 1995; Bell et al, 2009) and anxiety.(Mynors- Wallis 2005; Seekles et al, 2011) Most research has focused on depression.

Finally as she and her family understood the importance of compliance in psychotherapy, she was regular to the sessions and was following her homework assignments regularly and seriously. As the improvement in her condition was monitored during every session and she could acknowledge minute positive changes in her condition this would have added to improve her distress and prevent relapse.

\section{CONCLUSION}

It can be concluded that both mindfulness and CBT when employed together in the treatment of depression prove to be beneficial. Together both not only reduces the level of depression, stress perceived and cognitive distortions experienced but also enhances a sense of self efficacy, self esteem and skill of problem solving. Thus leading to a better life for the client.

\section{Acknowledgments}

The author appreciates all those who participated in the study and helped to facilitate the research process.

\section{Conflict of Interests}

The author declared no conflict of interests.

\section{REFERENCES}

American Psychiatric Association. (2000). Diagnostic and statistical manual of mental disorders (4th ed., text revision). Washington, DC: Author.

Baer, R. A., Smith, G. T., Hopkins, J., Krietemeyer, J., \& Toney, L. (2006). Using self-report assessment methods to explore facets of mindfulness. Assessment, 13, 27-45.

Bandura, A. (1997). Self-Efficacy: The exercise of control. New York: Freeman.

Beck, A. T. (1967). Depression: Clinical, experimental, and theoretical aspects. New York: Hoeber.

Beck, A. T. (1983). Cognitive therapy of depression: New perspectives. In P.J. Clayton \& J. E. Barett (Eds.), Treatment of depression: Old controversies and new approaches (pp. 265284). New York: Raven Press,.

Beck, A. T. (1987). Cognitive models of depression. Journal of Cognitive Psychotherapy: An International Quarterly, 1, 5-37.

Beck, A. T., Rush, A.J., Shaw, B., \& Emery, G. (1979). Cognitive therapy of depression. New York: Guilford.

Beck, A. T., Steer, R. A., \& Brown, G. K. (1996). BDI-II manual. San Antonio, TX: Psychological Corporation.

Beck, A. T., Steer, R. A., \& Brown, G. R. (1996). The Beck Depression Inventory (2 ${ }^{\text {nd }}$ ed.). San Antonio: Psychological Corporation. 


\section{Cognitive Behaviour Therapy and Mindfulness: hope for Depression}

Beck, J. S. (1995). Cognitive therapy: Basics and beyond. New York, NY: Guilford Press.

Bell, A. \&D'Zurilla (2009). Problem-solving therapy for depression: a meta-analysis. Clinical Psychology, 29, 348-53.

Bishop, M., Lau, S., Shapiro, L., et al. (2004). Mindfulness: a proposed operational definition. Clinical Psychology , 11, 230-41.

Burns (feeling good book reference) 1980.

Burns, D. D. \& Beck, A. T. (1978). Cognitive behavior modification of mood disorders. In J. P. Foreyt\& D. P. Rathjen (Eds.), Cognitive behavior therapy: Research and application (pp. 109-134). New York, NY: Plenum Press.

Burns, D. D. (1980). Feeling Good: The New Mood Therapy. New York: Avon Books.

Chen, S.Y. (2008). The mechanism of CBT for depression recovery: the role of problem solvingappraisal (unpublished doctoral dissertation). The University of Texas, Arlington.

Clark, D. A., Beck, A. T., \& Alford, B. A. (1999). Scientific foundations of cognitive theory and therapy of depression. New York: John Wiley \& Sons, Inc.

Dobson, K. S. \& Hamilton, K. E. (2003). Cognitive restructuring: Behavioral tests of negative cognitions. O’Donohue, W., Fisher, J. E., Hayes, S. C., Cognitive behavior therapy: Applying empirically supported techniques in your practice. Hoboken (pp.84-88). New Jersey: John Wiley \& Sons, Inc.

Dobson, K. S. \&Dozois, D.J.S (2009). Historical and philosophical bases of the cognitivebehavioral therapies. Dobson, K., Handbook of Cognitive-Behavioral Therapies $\left(3^{\text {rd }}\right.$ edition). New York: Guilford Press.

Dobson, K. S., \&Dozois, D. J. A. (2010). Historical and philosophical bases of the cognitive behavioral therapies. In K. S. Dobson (Ed.), Handbook of cognitive-behavioral therapies (3rd ed., pp. 3-38). New York: Guilford Press.

Dobson, K.S. (1989). A meta-analysis of the efficacy of cognitive therapy for depression. Journal of Consulting and Clinical Psychology, 57(3), 414-9.

D'Zurilla, T. \&Nezu, A. (1982). Social problem solving in adults. In: Kendall P, editor. Advances in cognitive-behavioural research and therapy (pp. 201-74). New York: Academic Press.

Frojan-Parga, M. X., Calero-Elvira, A., \& Montano-Fidalgo, M. (2009). "Analysis of the therapist's verbal behavior during cognitive restructuring debates: a case study". Psychotherapy Research, 19, 30-41. doi:10.1080/10503300802326046.

Gladding,S. (2009). Counseling:A Comprehensive Review (6 ${ }^{\text {th }}$ edition). Columbus: Pearson Education Inc.

Gotlib, I. \&Asarnow, R. (1979). Interpersonal and impersonal problem solving skills in mildly and clinically depressed university students. Journal of Consulting Clinical Psychology, 47, 86-95.

Hofmann, S. G., \&Asmundson, G.J. (2008). Acceptance and mindfulness-based therapy: new wave or old hat? Clinical Psychology Review, 28, 1-16.

Hofmann, S. G., Sawyer, A. T., Witt, A. A., \& Oh, D. (2010). The effect of mindfulness-based therapy on anxiety and depression: a meta-analytic review. Journal of Consulting Clinical Psychology, 78(2), 169-183.

Hofmann, S. G., Sawyer, A. T., Witt, A. A., \& Oh, D. (2010). The effect of mindfulness-based therapy on anxiety and depression: A meta-analytic review. Journal of Consulting and Clinical Psychology, 78(2), 169-183. 


\section{Cognitive Behaviour Therapy and Mindfulness: hope for Depression}

Hofmann, S.G. \& Smits, J. A. J. (2008). Cognitive-behavioral therapy for adult anxiety disorders: a meta-analysis of randomized placebo-controlled trials. Journal of Clinical Psychiatry, 69, 621-632.

Hollon, D. S., \&Dimidjian, S. (2009). Cognitive and behavioral treatment of depression. In I. H. Gotlib\& C. L. Hammen (Eds.), Handbook of depression (2nd ed., pp. 586-603). New York: Guilford Press.

Huppert J.D. (2009). "The building blocks of treatment in cognitive-behavioral therapy". Israel Journal of Psychiatry Related Science 46, 245-250.

Kabat-Zinn J. (2003) Mindfulness-based interventions in context: past, present, and future. Clinical Psychology, 10,144-56.

Kanter J.W., Schildcrout J.S., \&Kohlenberg R.J. (2005). "In vivo processes in cognitive therapy for depression:Frequency and benefits". Psychotherapy Research 15, 366-373. doi:10.1080/10503300500226316.

Keller, M. B., McCullough, J. P., Klein, D. N., Arnow, B., Dunner, D. L., \&Gelenberg, A. J. A comparison of nefazodone, the cognitive behavioral-analysis system of psychotherapy, and their combination for the treatment of chronic depression. The New England Journal of Medicine, 342(20), 1462-70. [Medline].

Kessler, R.C., Berglund, P.A. ,Demler, O., Jin, R., \&Walters, E. E. (2005). Archives of General Psychiatry, 62, 593-602.

Kuyken, W., Beck, A. T. (2007). Cognitive therapy. C. Freeman and M. Power (Eds.). Handbook of evidence-based psychotherapies: A guide for research and practice (pp.15-39). Chichester: Wiley.

Kuyken, W., Byford, S., Taylor, R. S., Watkins, Ed., holden, E., White, K., Barrett, B., Byng, R., Evans, A., Mullan, E., \& Teasdale, J.D. (2008). Mindfulness-based cognitive therapy to prevent relapse in recurrent depression. Journal of Consulting and Clinical Psychology,76,966-78.

Kuyken, W., Byford, S., Taylor, R. S., Watkins, E., Holden, E., White, K., et al. (2008). Mindfulness-based cognitive therapy to prevent relapse in recurrent depression. Journal of Consulting and Clinical Psychology, 76(6), 966-978.

Kuyken, W., Crane, R.,\&Dalgleish, T. (2012). Does mindfulness based cognitive therapy prevent relapse of depression? BMJ,345,e7194.

Ma, S. H., \& Teasdale, J. D. (2004). Mindfulness-Based Cognitive Therapy for Depression: Replication and Exploration of Differential Relapse Prevention Effects. Journal of Consulting and Clinical Psychology, 72(1), 31-40.

Marlatt, G. A., \& Gordon, J. R. (1985). Relapse prevention. New York: Guilford.

Marx, E. M., Williams, J. M. G., \&Claridge, G. C. (1992). Depression and social problem solving. Journal of Abnormal Psychology, 101, 78-86.

$\begin{array}{llll}\text { Mindfulness. } & \text { Retrieved } & \text { December } & \text { from }\end{array}$ http://www.helpguide.org/harvard/mindfulness.htm

Mynors-Wallis LM, Gath DH, Lloyd-Thomas AR, Tomlinson D. Randomised control trial comparing problem solving treatment with Amitryptyline and placebo for major depression in primary care. BMJ 1995;310:441-5.

Mynors-Wallis, L. (2005).Problem solving treatment for anxiety and depression. Oxford: OUP, 2005.

Perceived stress scale. Retrieved November 10, 2013, from http://www.macses.ucsf.edu/research/psychosocial/pss4.php 


\section{Cognitive Behaviour Therapy and Mindfulness: hope for Depression}

Perceived stress scale. Retrieved November 10, 2013, from http://www.macses.ucsf.edu/research/psychosocial/pss4.php

Rosenberg, M. (1965). Society and the adolescent self-image. Princeton, NJ: Princeton University Press.

Seekles, W., Van Straten, A., Beekman, A., Van Marwijk, H.,\&Cuijpers, P. (2011). Effectiveness of guided self-help for depression and anxiety disorders in primary care: a pragmatic randomized controlled trial. Psychiatry Research, 187, 113-20.

Segal, Z. V., Williams, J. M. G., Teasdale, J. D. (2002).Mindfulness-based cognitive therapy for depression: a new approach to preventing relapse. New York: Guilford Press.

Stark, K.D. \& Sander, J.B. (2002). Diagnostic and statistical manual brief symptom interview for depression(Unpublished Manuscript). University of Texas, Austin.

Teasdale, J. D., Segal, Z. V., Williams, J. M. G., Ridgeway, V. A., Soulsby, J. M., \& Lau, M. A. (2000). Prevention of Relapse/Recurrence in Major Depression by Mindfulness-Based Cognitive Therapy. Journal of Counselling and Clinical Psychology, 68(4), 615-623.

Vos, T., Corry. J., Haby. M. M., Carter. R., \& Andrews, G. (2005). Cost effectiveness of cognitive behavioural therapy \& drug intervention for major depression. Australian and New Zealand Journal of Psychiatry,39 (8), 683-692.

Vos, T., Haby, M. M., Barendregt, J. J., Kruijshaar, M., Corry, J., \& Andrews, G. (2004). The burden of major depression avoidable by longer-term treatment strategies. Archives of General Psychiatry, 61(11),1097-1103.

Williams, J. M., Teasdale, J. D., Segal, Z. V. \&Soulsby, J. (2000). Mindfulness-based cognitive therapy reduces overgeneral autobiographical memory in formerly depressed patients. Journal of Abnormal Psychology, 109, 150-155.

World Health Organisation (WHO). (2004). The Global Burden on Disease 2004 update. Reterived from www.who.int/healthinfo/global_burden_disease/GBD_report_2004update_full.pdf.

World Health Organization (2008). The Global Burden of Disease 2004 update. http://www.who.int/healthinfo/global_burden_disease/GBD_

report_2004 update_full.pdf Accessed 16.6.2012

Wright, J. H., Wright, A. S., Albano, A. M., Basco, M. R., Goldsmith, L. J., Raffield, T., et al. (2005). Computer assessed cognitive therapy for depression: Maintaining efficacy while reducting therapist time. American Journal of Psychiatry, 162, 1158-1164.

Wright, J.H. \& Mc Cray, L.W. (2011). Breaking Free from Depression: pathways to Wellness. New York: The Guilford Press.

Yurica, C. (2002). Inventory of Cognitive Distortions: Validation of a psychometric instrument for the measurement of cognitive distortions. Unpublished doctoral dissertation. Philadelphia College of Osteopathic Medicine.

Zapor, H. \& Stuart, G.L. (2015). Affirmative Cognitive Behavioural Therapy for a Male with Depression Following Sexual Orientation Discrimination. Clinical Case Studies, September 2015.

How to cite this article: M Sharma, A Hingar (2016), Cognitive Behaviour Therapy and Mindfulness: hope for Depression, International Journal of Indian Psychology, Volume 3, Issue 4, No. 58, ISSN 2348-5396 (e), ISSN: 2349-3429 (p), DIP: 18.01.042/20160304, ISBN: 978-1365-24976-1 